\title{
A Quantitative Approach to Identifying Turfgrass Key Players
}

\author{
B. Worley ${ }^{1}$, N. Fuhrman' ${ }^{2}$, J. Peake ${ }^{3}$
}

\begin{abstract}
The purpose of this study was to systematically identify key players and media channels within the turf industry to constitute the diffusion of innovations in emerging turf research and technologies. Online survey questions were structured using Borgatti's work developing the KeyPlayer ${ }^{\mathrm{TM}}$ (TM Analytic Technologies) software to determine individual contribution to a network and thus network cohesion. Turf industry professionals were asked to identify who they trust when they have questions regarding turfgrass. Researchers directly contacted 282 participants via email, collecting 239 responses. The top 25 key players, the number of distinct persons reached in the network, and the percent of the network reached were calculated for the entire sample and each strata of the sample (including golf course superintendents, landscapers, turf producers, Extension, and Othersincluding Extension Specialists, Turfgrass Faculty, and Sales representatives. Of the 422 unique names mentioned in the survey, key player data showed that the top 25 key players were 1 or 2 steps away from 305 distinct persons in the network (72.3\% of the network). With their influence on the larger network, these individuals will now be enlisted to aid in the diffusion of emerging new turf research and technologies.
\end{abstract}

\section{Keywords}

Diffusion of Innovations, elaboration likelihood model, link-tracing network sampling, network identification, decision-making model

1. Barbara Worley, Graduate Research Assistant, University of Georgia, 405 College Station Rd., Athens, GA 30602 , bworley@uga.edu, ID https://orcid.org/0000-0002-8490-2743

2. Nick Fuhrman, Professor, University of Georgia, 405 College Station Rd., Athens, GA 30602, fuhrman@uga.edu https://orcid.org/0000-0002-0969-0541

3. Jason Peake, Professor, University of Georgia, 405 College Station Rd., Athens, GA 30602, jpeake@uga.edu, https://orcid.org/0000-0002-1431-5447 


\section{Introduction and Problem Statement}

In science communication an "opinion leader" is "influential because others in the organization listen to them for advice or information" regarding an innovation (Stone et al., 1999, pp. 135, 138). The identification of a list of opinion leaders or key players - those with influence in a community - is a clear concept that is difficult to manifest in a real-world, diffusion of innovation scenario. Agriculture development and diffusion of innovation models thus far have primarily focused on the importance of engaging key players in efforts to disseminate researchbased information (Ruth et al., 2018). However, less work has been published on how to identify those key players.

Science is communicated in a variety of channels to the public, and how the receiver decodes the message depends on outside noise and the source from which the information is being disseminated. A range of issues regarding the source of scientific news include "(1) scientists as sources and resources, (2) journalists and their role in utilizing sources and resources, (3) public information officials as sources and resources, and (4) the science policy climate under which scientists, journalists, and public information officials work" (Logan, 2001, p. 144). Considering the increased availability of pseudo-science and misinformation about emerging and new technologies, it is of paramount importance to ensure that accurate information reaches the intended audience using the relevant channels (Schiele, 2020).

When new agricultural technologies are released into the market, there are important shifts in outreach efforts needed to reach broader audiences focused on key players and media channels to constitute the diffusion of innovation (Schwartz et al., 2020). Determining who is best suited to disseminate information throughout the network via social engagement can only be understood by knowing who within the network garners trust and is regarded as a leader.

\section{Theoretical and Conceptual Framework}

Turfgrass is an Agricultural and Natural Resource (ANR) commodity with a distinct population of stakeholders, gate keepers, and communication preferences and channels. This research is phase one of an effort to test a Decision-Making Model (DMM) for ANR (Ruth et al., 2018) that has yet to be applied the turfgrass industry. When planning how turfgrass advancements can be most effectively disseminated, a model is needed that reveals a path for information flow (Ruth et al., 2018). To apply this model, key players must be identified. Previous studies of the golf course superintendent stratum identified perceived transformational leadership traits as well as their position as "frontline decision makers in the industry's response to environmental issues" (Lenhardt et. al, 2011; Millington \& Wilson, 2013, p. 456).

This work utilizes Rogers (2003) Diffusion of Innovations Theory (Dol), where Rogers defines the process of diffusion as "1) an innovation 2) communicated through certain channels 3) over time 4) among members of a social system" (p. 12). Rogers (2003) states that communication is "a process in which participants create and share information with one another in order to 
reach a mutual understanding" (p. 5). The innovation of new turfgrass cultivars must be communicated using various channels over time (dynamic) among various strata within the turfgrass industry. Individuals go through different stages when deciding whether or not to adopt new innovations (Masambuka-Kanchewa, 2020, p. 118). These five stages of the Dol, as outlined by Rogers (2003), are "knowledge, persuasion, decision, implementation, and confirmation" (p. 20).

In order to acquire knowledge about the innovation they must be aware of the innovation's existence and then have knowledge about the innovation (Rogers, 2003, p. 173). Rogers (2003) refers to this as "awareness knowledge" (p. 173). "The effectiveness of communication channels in diffusing innovations depends on which stage a person is in during the decisionmaking process" (Masambuka-Kanchewa, 2020, p. 118). Therefore, the manner by which awareness is created about an innovation is determined by the communication channel that is used in delivering information regarding the innovation. As such, tailored and intentional messaging for target audiences is critical (Lamm et al., 2019).

Though the role of the innovator in Roger's theory is creating new ideas and, in this case, those developing new cultivars, it is the opinion leader - those that have been identified as key players - that have the most influence on communicating the new research to various industry strata. The persuasion stage of diffusion is thus salient to this research as clients must have an active cognitive need for seeking new information, leading to either a desirable or undesirable opinion of the innovation (Rogers, 2003, pp. 174-175). As illustrated in the DMM (Ruth et al., 2018), the Dol outlines the "perceived characteristics of innovation" having an impact on the persuasion stage as "relative advantage, compatibility, complexity, trialability, and observability" (Rogers, 2003, p. 170). Key players have the potentiality of becoming change agents if the communication they disseminate leads to the adoption of the innovation (Rogers, 2003, p. 175). Knowing the key players in the southeastern turfgrass industry will ensure more efficient communication and potential adoption of new innovations.

The Elaboration Likelihood Model (ELM) (Petty \& Cacioppo, 1980) purports that people make decisions about new innovations based on Central Route Processing where they listen to and evaluate the message pros and cons; or Peripheral Route Processing where they listen to social norms, rule of thumb, and cues. The ELM tests the "motivation to process a message and the "ability to process the message", thus overlapping with Rogers' idea of persuasion to determine motivation and ability to process the communication (Stone, 1999, pp. 194-195).

\section{Purpose}

The overall purpose for the larger study is to refine and focus a DMM for ANR Science and Technology, that could later be adopted by other fields, by integrating the theories of Diffusion of Innovations and the Elaboration Likelihood Model with our findings from link-tracing

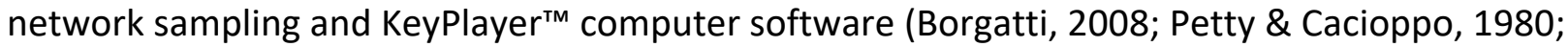
Rogers, 2003). In order to accomplish that, the purpose of this study is to identify key players in 
the southeastern turf industry and determine their preferred communication preferences. Knowing their communication preferences will be important in order to determine the best route for dissemination of communications regarding new turfgrass technologies. As such, the objectives for this study are to:

1. Identify influential individuals of the turf industry, referred to as "key players," by professional affiliation.

2. Describe the relationship between key players by professional affiliation and their communication preference.

\section{Methods}

This quantitative study aimed to target turf producers, Extension Agents, golf course superintendents, landscapers, and home builders as part of a larger study to determine a communication and decision-making model for innovations in turfgrass. An online survey was distributed in four rounds beginning Spring 2020 to the sample using the Tailored Design Method (Dillman et al., 2014), and data were collected using Qualtrics. Online survey questions, presented to the sample through an introductory email that provided a link to the instrument, were structured using Borgatti's work developing the KeyPlayer"m software to determine "the contribution of a set of actors to the cohesion of the network" (Borgatti, 2006, p. 21). A panel of Agricultural Leadership, Education and Communication faculty were used to review the questions as well as provide feedback on the content, criterion, and content validity.

Respondents ( $n=239$ ) were asked which of the roles (strata) they most closely identified with in the turf industry. Options for response included Extension agent, turf producer, golf course superintendent, landscaper, home builder, researcher, and other. When "other" was selected respondents were given a textbox to self-identify their role; for example, responses included Extension Specialist, Turfgrass Faculty, and Sales Representative. Quantitative descriptive research questions included in the instrument were demographic and solicited participants to identify who they trust when they have questions regarding turfgrass. Additionally, as part of a larger study, respondents were asked questions regarding the format they preferred receiving communication regarding turfgrass, how often they preferred receiving information, and what time of year (season) is best to receive information.

The researchers used a variant of respondent-driven sampling known as link-tracing sampling to reach individuals across various parts of the turfgrass industry (Gile \& Handcock, 2010, p. 285). The initial sample for Round 1 was selected from prior contacts in the population of interest from team members of the five universities that are part of a turfgrass Specialty Crop Research Initiative grant. Throughout four rounds of inquiry, researchers directly contacted 282 participants via email, collecting 239 responses. In Round 2, researchers utilized professional organizations for turfgrass producers and golf course superintendents. These organizations would not allow researchers access to the membership listservs; however, they would send emails on behalf of the researchers. From this, a population frame of 712 for Round 2 could be determined. Table 1 details each of the four rounds of data collection, including response rate. 
Table 1

Response Rates for each Round of Data Collection

\begin{tabular}{lcccc}
\hline & Round 1 & Round 2 & Round 3 & Round 4 \\
\hline Sample & 45 & 712 & 116 & 42 \\
Responses & 37 & 172 & 19 & 11 \\
Response Rate & $82.20 \%$ & $24.60 \%$ & $16.40 \%$ & $26.20 \%$ \\
\hline
\end{tabular}

Limitations of the research were confounded by the global pandemic of COVID-19 that limited data collection to being electronically based. Identifying which strata to survey was limited to the researchers' knowledge of contacts. Determining where to start the sampling may have skewed the proportion of respondents in certain professional segments of the industry or strata. Kirchherr and Charles (2018) refer to using prior personal or professional contacts in the absence of a sampling frame to serve as the seeds of the sample (p. 4). Because of this and the utilization of a non-probability sampling methodology, bias may have occurred. To address these limitations, data collection continued until a redundancy of responses of the same subjects was seen (S. Borgatti, personal communication, January 8,2020 ). An additional limitation is that strata was self-reported by the subjects given the option to select only one choice. Some subjects may have difficulty identifying themselves within a single stratum, when in reality they play different roles in different strata yet were only allowed to select a single stratum in the instrument.

Data were analyzed using the Statistical Package for the Social Sciences (SPSS) version 26 and Excel, and social network analysis was performed. Respondents were assigned a unique identifier as were those that they listed as trusted individuals. Four hundred and twenty-two unique names were identified. This data was placed into the KeyPlayer ${ }^{\mathrm{TM}}$ to create a statistical and graphical representation of the nodes (points of contact within the network) represented.

\section{Findings}

The findings are presented respective to the objectives of this study.

\section{Identification of Key Players in Strata of the Turfgrass Industry}

Table 2 details the top 25 key players, the number of distinct persons reached in the network, and the percent of the network reached. Of the 422 unique names mentioned in the survey, key player data showed that the top 25 key players were 1 or 2 steps away from 305 distinct persons (72.3\% of the network). In other words, the node that is most central, within 1 or 2 nodes from others, provides a larger reach over the network. 


\section{Table 2}

Top 25 Key Players in the Turfgrass Network

\begin{tabular}{cccc}
\hline Number & Key Player $^{\mathrm{a}}$ & Influenced $^{\mathrm{b}}$ & \% of Network $^{\text {(n) }}$ \\
\hline 1 & 5 & 90 & 21.3 \\
2 & 6 & 126 & 29.9 \\
3 & 23 & 157 & 37.2 \\
4 & 27 & 176 & 41.7 \\
5 & 30 & 190 & 45.0 \\
6 & 36 & 213 & 50.5 \\
7 & 61 & 198 & 46.9 \\
8 & 65 & 206 & 48.8 \\
9 & 69 & 220 & 52.1 \\
10 & 102 & 227 & 53.8 \\
11 & 195 & 234 & 55.5 \\
12 & 202 & 240 & 56.9 \\
13 & 225 & 246 & 58.3 \\
14 & 232 & 252 & 59.7 \\
15 & 246 & 258 & 61.1 \\
16 & 249 & 263 & 62.3 \\
17 & 252 & 268 & 63.5 \\
18 & 261 & 273 & 64.7 \\
19 & 264 & 278 & 65.9 \\
20 & 266 & 283 & 67.1 \\
21 & 274 & 288 & 68.2 \\
22 & 300 & 293 & 69.4 \\
23 & 324 & 297 & 70.4 \\
24 & 332 & 301 & 71.3 \\
25 & 349 & 305 &
\end{tabular}

a Number assigned to each individual

${ }^{b}$ Number of persons influenced by increase in reach.

To graphically display the key player data results, Pajek (Mrvar \& Batagelj, 2016) analysis and visualization software was used. Pajek creates various 2-D and 3-D visualization outputs; our study used a 2-D SVG format with the Kamada-Kawai optimization network layout.

In the 2-D Pajek model, seen in Figure 2, the more connected the node under this model, the more centrally located. Single outliers are shown for reasons including that data collection ended at round four or that those nodes were included as unique persons but their data of those they trust was not collected for the model. 
Figure 1

Pajek 2-D of Turfgrass Network

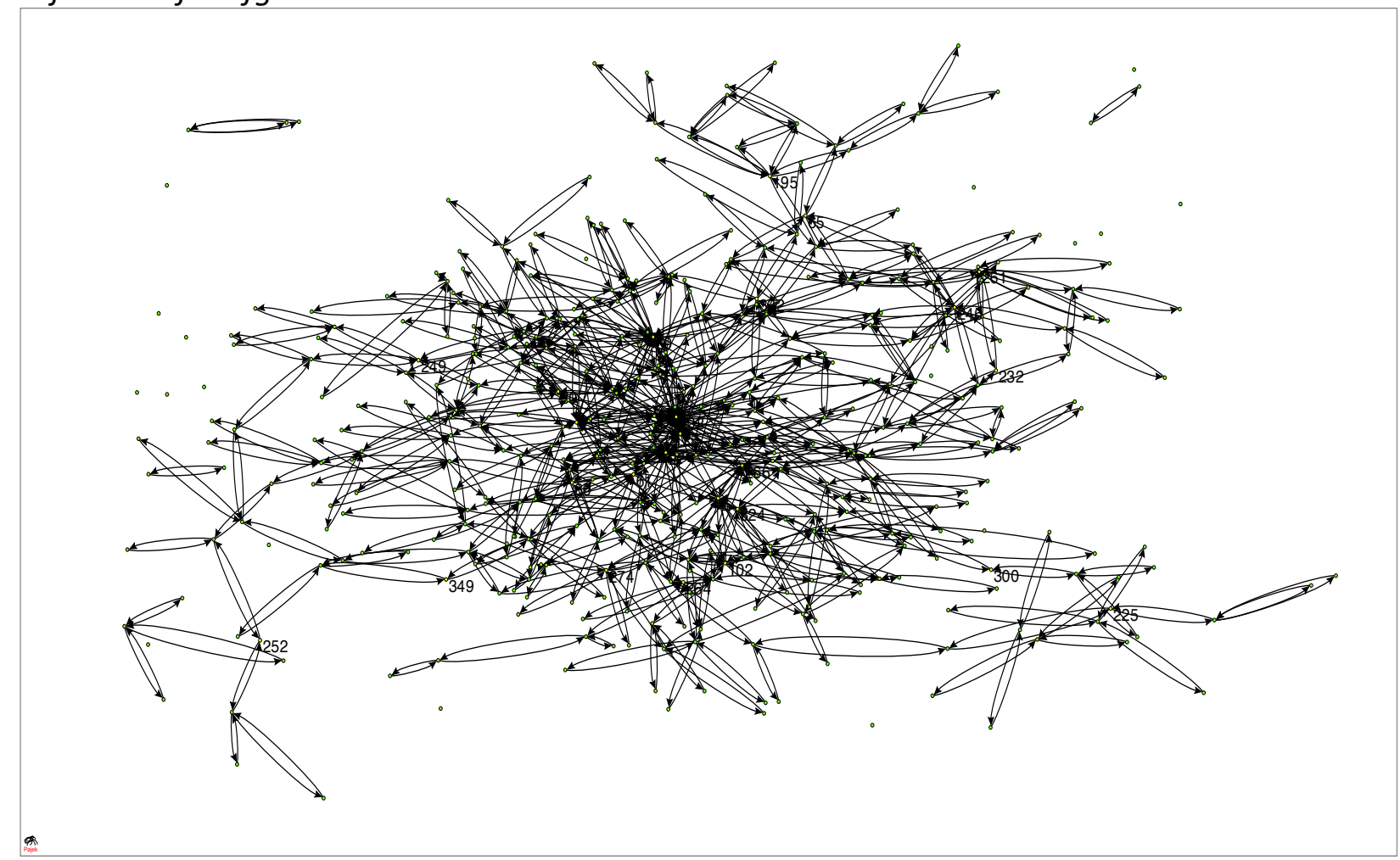

Note. Key Players are indicated by their corresponding numerical identifier.

We were able determine the key players within each stratum (as indicated in the instrument), by segmenting the sample into the five strata (golf course superintendent, Extension agent, turf producer, landscaper, and other) as identified by respondents from the instrument and running a KeyPlayer ${ }^{\mathrm{TM}}$ analysis to determine bi-directional trust (i.e., who is influenced by the strata, and who the strata influences). As shown in Table 3 and Table 4, Golf course superintendents and Other emerged as the strata with the most influence over the network, with a total combined influence of all five strata equally greater than $100.0 \%$ due to cross-strata influence. Further, cross-strata influence is revealed indicating that key players emerge within individual strata to which they do not necessarily identify. For example, respondent 2 is the top key player within their strata (turf producer), as well as the landscaper strata. Likewise, respondent 6 is the top key player within their strata (other), as well as the Extension strata. Respondent 6 identified themselves as "Extension Specialist" in the text box that was provided for the other strata. The level of influence increases with the person identified as being closer to the top of the list.

Moving down the list, the strength of influence decreases. These findings ultimately reveal the key players in the turf industry who can impact the maximum amount of the network through unique connections, as a whole, and within and between each stratum. 


\section{Table 3}

Top 25 Key Players within Each Stratum

\begin{tabular}{|c|c|c|c|c|}
\hline $\begin{array}{c}\text { Golf Course } \\
\text { Superintendent }\end{array}$ & Landscaper & Other & Turf Producer & Extension \\
\hline 5 & 2 & 6 & 2 & 6 \\
\hline 61 & 3 & 20 & 24 & 9 \\
\hline 69 & 4 & 23 & 36 & 18 \\
\hline 102 & 5 & 27 & 60 & 21 \\
\hline 113 & 8 & 36 & 78 & 40 \\
\hline 182 & 9 & 44 & 112 & 46 \\
\hline 200 & 10 & 48 & 120 & 71 \\
\hline 202 & 11 & 50 & 123 & 94 \\
\hline 233 & 12 & 137 & 132 & 109 \\
\hline 243 & 13 & 170 & 153 & 148 \\
\hline 249 & 14 & 197 & 165 & 154 \\
\hline 252 & 20 & 205 & 207 & 164 \\
\hline 264 & 23 & 220 & 213 & 179 \\
\hline 266 & 24 & 224 & 265 & 195 \\
\hline 268 & 25 & 231 & 274 & 202 \\
\hline 274 & 27 & 261 & 316 & 207 \\
\hline 281 & 29 & 268 & 324 & 244 \\
\hline 300 & 31 & 325 & 330 & 264 \\
\hline 303 & 33 & 346 & 337 & 277 \\
\hline 315 & 35 & 368 & 338 & 287 \\
\hline 332 & 36 & 387 & 339 & 293 \\
\hline 349 & 37 & 395 & 352 & 346 \\
\hline 358 & 196 & 396 & 354 & 364 \\
\hline 372 & 204 & 398 & 382 & 398 \\
\hline 385 & 228 & 410 & 410 & 399 \\
\hline
\end{tabular}




\section{Table 4}

Network Reach, Influence, and Identification

\begin{tabular}{lccccc}
\hline & Golf Course & & \multicolumn{3}{c}{ Turf } \\
& Superintendents & Landscapers & Other & Producers & Extension \\
\hline \% of Network reached $^{\text {a }}$ & 48.6 & 9.2 & 31.5 & 14.2 & 12.3 \\
\# of persons influenced $^{\mathrm{b}}$ & 205 & 39 & 133 & 60 & 52 \\
\# within stratum identified $^{c}$ & 6 & 2 & 12 & 4 & 2 \\
\hline
\end{tabular}

${ }^{a}$ The $\%$ of the entire turfgrass network reached, by which each strata were influenced or influential.

${ }^{b}$ The number of persons influenced, within 1 or 2 steps, by the top 25 key players of each strata.

c The number of key players that emerged within each stratum, possessing the same identity, is indicated by number, having influence on their own stratum.

\section{Relationship Between Key Players by Stratum and their Communication Preference}

The preferred method of communication was established across all strata and within each stratum, in relation to the second objective. As shown in Table 5, the findings revealed that the preferred communication channel across all strata was "Face to Face conversations with professionals" (interpersonal communication) at 51.4\%.

\section{Table 5}

Top Communication Channel by Strata

\begin{tabular}{llc}
\hline Strata & Preferred communication channel & Percent of strata \\
\hline Extension Agents & Email correspondence with professionals & 38.9 \\
Turf Producers & Communication with peers & 42.1 \\
Golf Course Superintendents & $\begin{array}{l}\text { Face to Face conversations with } \\
\text { professionals }\end{array}$ & 62.0 \\
Landscapers & $\begin{array}{l}\text { Face to Face conversations with } \\
\text { professionals } \\
\text { Longer (more than 1 full day) conferences }\end{array}$ & \\
Other & & \\
& Face to Face conversations with \\
professionals & 43.2
\end{tabular}

Note. An equal proportion of the Landscapers and Other strata had preference for two channels.

${ }^{\text {a }}$ Other included those who self-reported as being anything other than the strata listed in the instrument. 


\section{Conclusions, Discussion, and Recommendations}

Through the use of the KeyPlayer ${ }^{\mathrm{TM}}$ (TM Analytic Technologies) program (Borgatti, 2008), we identified key players in the turfgrass industry to maximize diffusion of innovation and increase adoption rates of new cultivars and turf technologies. This study found that there are key players that exist within the southeastern turfgrass network that can be targeted to disseminate communications of new turf industry technologies and research throughout the network. Social network analysis through the use of KeyPlayer ${ }^{\mathrm{TM}}$ and the concept of group centrality, as used in this study, can be used as an "identifier of opinion leaders" (Abdel-Ghany, 2012, p. 12-13).

A primary finding from this study was that the top 25 key players in the network are 1 to 2 steps away from $72.3 \%$ of the network. Thus, these top key players have the potential to serve as opinion leaders due to their central positioning within the network and established relationships among others in the industry. When considering Rogers (2003) Diffusion of Innovations theory where $16.0 \%$ to $50.0 \%$ of the population represents the early majority adopters, identifying 25 individuals who influence $72.3 \%$ of the network as opinion leaders should diffuse the emerging technology and research well into the early majority if not the late majority $(50.0 \%$ to $84.0 \%)$ of subjects.

Now that key players and who the key players trust have been identified within the turfgrass network it is possible to trace which key players trust which members of the research team. The members of the research team will reach out to KeyPlayers who trust them to solicit their participation in a steering committee to disseminate new turfgrass innovations.

Recommendations associated with future research are outlined addressing demographics, strata selection and response, and communication channels. Respondents were asked to selfidentify in the demographics section, but were not asked to provide the stratum of those they listed they "trust" when answering "Who do you trust when you have questions regarding turfgrass?" By providing this information in the future, if those individuals are not captured in subsequent rounds of query, their stratum will still be noted. This will provide a more detailed analysis of the communication preferences of the strata represented in the network. A recommendation to address the strata indicated as other is to eliminate the option of providing that selection in the instrument, thereby guiding individuals to identify with one of the strata defined.

A recommendation for determining generational differences among respondents is in line with the literature. Lamm et. al (2019) suggested identifying characteristics of the target audiences and developing targeted communication based on specified needs and interests. Perhaps greater variation exists between contextual variables (age, gender, etc.) of subjects than between strata. Further, we did not seek to determine change agents, but rather to identify key players based on level of trust within the network. As Flynn et. al (1996) noted in their study, opinion leaders and opinion seekers are distinct groups (p. 2). However, in this study we sought 
to determine the trusted individuals within the network. Future research on determining how key players act as change agents is recommended.

Preference in communication channels should be more closely examined in conjunction with examining adoption rates of new technologies. Determining why face to face communication is preferred will give researchers insight in to how turfgrass information can be more effectively disseminated. Additionally, alternative to face-to-face communication should be explored and discussed across strata due to the implications of this form of interpersonal communication during a global pandemic. The model for decision-making by each stratum of the turfgrass industry should be refined with each iteration and the decision-making model should be revised to increase adoption rates.

We are now building a customized training and diffusion plan for new turfgrass technology and research. This systematic approach to communication in the turfgrass industry can be implemented and will enable opinion leaders to disseminate information of new cultivars and other industry related research-based information. This decision-making model will be implemented and studied to continuously improve its reliability and validity.

\section{References}

Abdel-Ghany, M. (2012). Identifying opinion leaders using social network analysis, a study in an Egyptian village. Russian Journal of Agricultural and Socio-Economic Sciences, 4(4) 1219.

https://www.researchgate.net/publication/285173471 Identifying opinion leaders usi ng social network analysis a study in an Egyptian village

Borgatti, S. (2008, June 23). The Key Player Problem. SSRN. https://papers.ssrn.com/sol3/papers.cfm?abstract id=1149843

Borgatti, S. P. (1999, January 1). Identifying sets of key players in a social network. Computational and Mathematical Organization Theory. https://link.springer.com/article/10.1007/s10588-006-7084-x

Burt, R. S. (1999). The social capital of opinion leaders. Annals of the American Academy of Political and Social Science, 566, 37-54. https://journals.sagepub.com/doi/10.1177/000271629956600104

Dillman, D. A., Smyth, J. D., \& Christian, L. M. (2014). Internet, mail, and mixed-mode surveys: The tailored design method. (4th ed.). Wiley \& Sons, Inc.

Flynn, R. L., Goldsmith, R. E., \& Eastman, J. K. (1996, March). Opinion leaders and opinion seekers: Two new measurement scales. Journal of the Academy of Marketing Science. https://link.springer.com/article/10.1177/0092070396242004 
Gile, K. J., \& Handcock, M. S. (2010). Respondent-driven sampling: An assessment of current methodology. Sociological Methodology, 40(1), 285-327. https://doi.org/10.1111/j.14679531.2010.01223.x

Kirchherr, J., \& Charles, K. (2018). Enhancing the sample diversity of snowball samples: Recommendations from a research project on antidam movements in Southeast Asia. PLoS ONE, 13(8) Article e0201710. https://doi.org/10.1371/journal. pone.0201710

Lamm, K. W., Borron, A., \& Holt, J. (2019). Communication channel preferences: A descriptive audience segmentation evaluation. Journal of Applied Communications, 103(3). https://doi.org/10.4148/1051-0834.2238

Lenhardt, M., Ricketts, J.C., Morgan, A. C., \& Karnock, K. J. (2011, December). Leadership behaviors of Georgia golf course superintendents: Implications for post-secondary programs. North American Colleges and Teachers of Agriculture, 55(4), 23-30. https://www.jstor.org/stable/10.2307/nactajournal.55.4.23

Logan, R. A. (2001,). Science mass communication: Its conceptual history. Sage Journals, 23(2), 135-163. https://doi.org/10.1177/1075547001023002004

Masambuka-Kanchewa, F., Rodriguez, M., Buck, E., Niewoehner-Green, J., \& Lamm, A.(2020). Impact of agricultural communication interventions on improving agricultural productivity in Malawi. Journal of International Agricultural and Extension Education, 27(3), 116-131. https://doi.org/10.5191/jiaee.2020.273116

Millington, B., \& Wilson, B. (2013). Super intentions: Golf course management and the evolution of environmental responsibility. The Sociological Quarterly, 54(3), 450-475. https://doi.org/10.1111/tsq.12033

Mrvar, A., \& Batagelj, V. (2016, April 6). Analysis and visualization of large networks with program package pajek. Complex Adaptive Systems Modeling, 4(6). https://doi.org/10.1186/s40294-016-0017-8

Petty, R. E., \& Cacioppo, J. T. (1986). The elaboration likelihood model of persuasion. Advances in Experimental Social Psychology, 19, 123-205. https://www.sciencedirect.com/science/article/pii/S0065260108602142

Rogers, E. M. (2003). Diffusion of innovations. (5th ed.). Free Press.

Ruth, T., Rumble, J., Lamm, A., \& Ellis, J. (2018). A model for understanding decision-making related to agriculture and natural resource science and technology. Journal of Agricultural Education, 59(4), 224-237. https://doi.org/10.5032/jae.2018.04224 
Schiele, A. (2020). Pseudoscience as media effect. Journal of Science Communication. 19(2). https://doi.org/10.22323/2.19020101

Schwartz, B., Peake, J., Fuhrman, N., \& Worley, B. (2020, Nov. 7). Using key player and decisionmaking models to increase diffusion of innovations in turf. [Conference session]. Crop Science Society of America. Phoenix, AZ, United States.

(C) 2021 by authors. This article is an open access article distributed under the terms and conditions of the Creative Commons Attribution license http://creativecommons.org/licenses/by/4.0/). 